University of Nebraska - Lincoln

DigitalCommons@University of Nebraska - Lincoln

Cannabinoid receptor expression and phosphorylation are differentially regulated between male and female cerebellum and brain stem after repeated stress: Implication for PTSD and drug abuse

\author{
Guoqiang Xing \\ Uniformed Services University of the Health Sciences, gxing99@yahoo.com \\ Janis Carlton \\ Uniformed Services University of the Health Sciences \\ Lei Zhang \\ Uniformed Services University of the Health Sciences \\ Xiaolong Jiang \\ Uniformed Services University of the Health Sciences \\ Carol Fullerton \\ Uniformed Services University of the Health Sciences

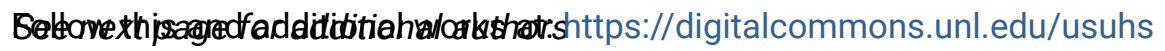 \\ Part of the Medicine and Health Sciences Commons
}

Xing, Guoqiang; Carlton, Janis; Zhang, Lei; Jiang, Xiaolong; Fullerton, Carol; Li, He; and Ursano, Robert, "Cannabinoid receptor expression and phosphorylation are differentially regulated between male and female cerebellum and brain stem after repeated stress: Implication for PTSD and drug abuse" (2011). Uniformed Services University of the Health Sciences. 77.

https://digitalcommons.unl.edu/usuhs/77

This Article is brought to you for free and open access by the U.S. Department of Defense at DigitalCommons@University of Nebraska - Lincoln. It has been accepted for inclusion in Uniformed Services University of the Health Sciences by an authorized administrator of DigitalCommons@University of Nebraska Lincoln. 
Authors

Guoqiang Xing, Janis Carlton, Lei Zhang, Xiaolong Jiang, Carol Fullerton, He Li, and Robert Ursano 


\title{
Cannabinoid receptor expression and phosphorylation are differentially regulated between male and female cerebellum and brain stem after repeated stress: Implication for PTSD and drug abuse
}

\author{
Guoqiang Xing*, ${ }^{*}$, Janis Carlton ${ }^{1}$, Lei Zhang, Xiaolong Jiang, Carol Fullerton, He Li, Robert Ursano \\ Department of Psychiatry, Uniformed Services University of the Health Sciences, Bethesda, MD 20814-4799, United States
}

\section{A R T I C L E I N F O}

\section{Article history:}

Received 29 March 2011

Received in revised form 22 April 2011

Accepted 4 May 2011

\section{Keywords:}

Sex-dimorphism

Traumatic stress

Cerebellum

Brain stem

Cannabinoid receptor

\begin{abstract}
A B S T R A C T
Recent study demonstrated a close relationship between cerebellum atrophy and symptom severity of pediatric maltreatment-related posttraumatic stress disorder (PTSD). It has also been known that females are more vulnerable than males in developing anxiety disorders after exposure to traumatic stress. The mechanisms are unknown. Because cannabinoid receptors $\left(\mathrm{CB}_{1}\right.$ and $\left.\mathrm{CB}_{2}\right)$ are neuroprotective and highly expressed in the cerebellum, we investigated cerebellar CB expression in stressed rats. Young male and female Sprague-Dawley rats were given 40 unpredictable electric tail-shocks for $2 \mathrm{~h}$ daily on 3 consecutive days. $\mathrm{CB}_{1}$ and $\mathrm{CB}_{2} \mathrm{mRNA}$ and protein levels in rat cerebellum and brain stem were determined using quantitative real-time PCR and Western blot, respectively. Two-way ANOVA revealed significant gender and stress effects on cerebellar $\mathrm{CB}_{1}$ mRNA expression, with females and non-stressed rats exhibiting higher $\mathrm{CB}_{1}$ mRNA levels than the males ( 3 fold, $p<0.01$ ) and stressed rats $\left(30 \%, p<0.01\right.$ ), respectively. $\mathrm{CB}_{1}$ and $\mathrm{CB}_{2}$ mRNA levels in brain stem were also greater in female rats than males $(p<0.01, p<0.05$, respectively). Repeated stress increased the level of phosphorylated $C_{1}$ receptors, the inactivated $C_{1}$, in rat cerebellum $(p<0.01)$, particularly in female rats as revealed by the significant gender $\times$ stress interaction. Thus, repeated severe stress caused greater $C_{1}$ mRNA suppression and $C B_{1}$ receptor phosphorylation in female cerebellum that could lead to increased susceptibility to stress-related anxiety disorders including PTSD.
\end{abstract}

(c) 2011 Elsevier Ireland Ltd. All rights reserved.
Mounting evidence implicates a critical role of cannabinoid receptors $\left(\mathrm{CB}_{1}\right.$ and $\left.\mathrm{CB}_{2}\right)$ in stress-related anxiety disorders and emotional memory. $\mathrm{CB}_{1}$ knockout animals show hypersensitivity to stressful stimuli, decreased sociability, increased aggressive and anxiety-like behaviors and disrupted response to anxiolytic drugs $[19,28,46] . \mathrm{CB}_{1}$ knockout animals and $\mathrm{CB}_{1}$ antagonist-treated animals also show marked inability to extinguish fear memory [27]. These characteristics parallel the core clinical features of individuals with post-traumatic stress disorder (PTSD), i.e. reduced threshold of fear, impaired extinction of fear memory, vivid recall or flashbacks of traumatic memories and a high prevalence of cannabis abuse $[23,36,49]$.

Despite the highest expression of cannabinoid receptors $\left(\mathrm{CB}_{1}\right.$ and $\mathrm{CB}_{2}$ ) found in the cerebellum $[20,25,48]$, its functional role remains to be established. To our knowledge, no one has reported

\footnotetext{
* Corresponding author at: Center for the Study of Traumatic Stress, Department of Psychiatry, Uniformed Services University of the Health Sciences, 4301 Jones Bridge Road, Bethesda, MD 20814-4799, United States. Tel.: +1 240643 6362; fax: +1 3012951042 .

E-mail address: gxing99@yahoo.com (G. Xing).

1 Equal contributors of this work.
}

cerebellar cannabinoid receptor expression under stressed conditions.

It is known that females are more vulnerable to traumatic stress and show a higher prevalence of stress-related anxiety disorders than males (2-3 fold) [7,39]. Yet many animal model studies of stress are based on male animals only; the generalizability of the male animal-based findings for females is limited accordingly. In this study, we examined $\mathrm{CB}_{1}$ and $\mathrm{CB}_{2}$ expression levels in the cerebellum and brain stem of young adult male and female rats, and the responses to repeated tail-shock stress.

Young juvenile male and female Sprague-Dawley rats (Taconic Farms, Germantown, NY, USA) weighing 100-150g (5-6 weeks old) were unisex and pair-housed, with wood chip bedding, and maintained at a room temperature of $22 \pm 2{ }^{\circ} \mathrm{C}$ on a 12-h light-dark schedule (lights on $1800 \mathrm{~h}$ ), and left undisturbed for 7 days before the start of the stress protocol that consisted of one 2-h per day session of restraint immobilization stress plus unpredictable repeated tail-shocks over 3 consecutive days. The animals were restrained in a Plexiglas tube and given 40 electric shocks $(2 \mathrm{~mA}, 3 \mathrm{~s}$ duration) at varying intervals (140-180 s). Animals in the control group were handled daily as those in the stress group, but without going through the stress procedure. 
After the last stress session on day 3, both the control animals and the stressed animals were decapitated after light anesthesia with halothane. The brains were rapidly removed, dissected and kept at $-70^{\circ} \mathrm{C}$ for real-time PCR and western blotting (Appendix 1 ). Half of the dissected cerebellum and brain stem of each animal were homogenized for total RNA extraction with RNeasy kit (Qiagen) and reverse transcription into first-strand cDNA with a reverse transcriptase kit (Sigma, St. Louis).

The qPCR and western blot data were represented as mean \pm s.d. The effects of gender and repeated stress on $\mathrm{CB}_{1}$ and $\mathrm{CB}_{2}$ receptor expression and phosphorylation in cerebellum and brain stem were analyzed using two-way ANOVA. As significant gender $\times$ stress interactions were found in $\mathrm{CB}_{1}$ mRNA expression and receptor phosphorylation, one-way ANOVA was conducted to evaluate the effect of stress within each sex. $p<0.05$ was considered statistically significant.

The qPCR data showed that $\mathrm{CB}_{1}$ mRNA levels were much higher than $C_{2}$ mRNA in the cerebellum and brain stem of both male and female control rats as shown by the $\mathrm{CB}_{1}: \mathrm{CB}_{2}$ mRNA ratio ( $>30$ fold) based on the $\mathrm{Ct}$ values of each receptor (Appendix 2). This is consistent with previous findings of high $\mathrm{CB}_{1}$ expression in cerebellum [20].

Two-way ANOVA revealed significant main effects of gender $(p<0.01)$ and repeated stress $(p<0.01)$, as well as significant gender $\times$ stress interaction $(p<0.01)$ on $\mathrm{CB}_{1}$ mRNA expression in rat cerebellum, with females and non-stressed rats exhibited higher $\mathrm{CB}_{1}$ mRNA levels than the males (3 fold) and stressed rats (30\%), respectively (Fig. $1 \mathrm{~A}$ ). The significant gender $\times$ stress interaction suggests a greater stress-induced reduction of $C_{1}$ mRNA in the female cerebellum $(p<0.01)$ than in males $(p<0.05)$ as revealed by the within-sex 1-way ANOVA (Fig. 1A). Two-way ANOVA showed significant gender, but no stress effect on $\mathrm{CB}_{1}$ mRNA expression level in the brain stem, with female rats showing higher level than male rats $(p<0.01)$ (Fig. 1B). $\mathrm{CB}_{2}$ mRNA expression level tended to be greater in the cerebellum and significantly greater in the brain stem $(p<0.05)$ of female rats than males (Fig. 1C and D). No significant stress effect was found in brain stem $\mathrm{CB}_{2}$ mRNA.

No significant gender and stress effects were found on total $\mathrm{CB}_{1}$ and $\mathrm{CB}_{2}$ proteins expressed in rat cerebellum and brain stem (Figs. 2 and 3). However, phosphorylated $C_{1}$ receptor $\left(p-C_{1}\right)$, the inactivate form of $C_{1}$ receptors, was significantly increased in the cerebellum of the stressed rats (2-way ANOVA, $p<0.01$ ), especially in the stressed females (Fig. 2A). Further, a significant stress $\times$ gender interaction existed in cerebellar $\mathrm{p}-\mathrm{CB}_{1}$ protein level suggesting a greater $\mathrm{p}-\mathrm{CB}_{1}$ level in the female cerebellum as supported by the within-sex 1 -way ANOVA $(p<0.01)$ (Fig. 2A). Because $C_{1}$ receptor phosphorylation has been shown to be associated with increased internalization and desensitization of $\mathrm{CB}_{1}$ receptors [18], the increased $p-C_{1}$ receptors suggest increased inhibition of $C_{1}$ receptor activity in the cerebellum of stressed animals.

The gender difference in cerebellar $\mathrm{CB}_{1}$ and $\mathrm{CB}_{2}$ mRNA expression is consistent with the reports of greater endocannabinoid content in the brains of female rats [5] and a greater $\mathrm{CB}_{1}$ mRNA expression in the blood cells of female human subjects [34]. Gender differences have also been reported in the amount of self-administered $\mathrm{CB}_{1}$ agonists, in brain metabolism and behavioral effects of $\delta^{9}$-tetrahydrocannabinol ( $\delta^{9}$-THC, the main active component of marijuana and potent $\mathrm{CB}_{1}$ agonist) in rodents, with females self-administering more $\mathrm{CB}_{1}$ agonists, producing significantly more of the active metabolite of THC and enhanced THC-induced behavioral effects including antinociception, motoric effects, catalepsy and hypothermia $[10,16,33,44,45]$. Although the mechanism is unknown, sex hormones and the estrous cycle may be involved in the gender difference in $\mathrm{CB}_{1}$ and $\mathrm{CB}_{2}$ receptor expression. There are reports that ovariectomy (OVX) decreased, whereas acute and chronic estradiol or progesterone administra- tion increased the density of cannabinoid receptors in the limbic forebrain and in the hypothalamic nucleus of intact and OVX female rats [40]. As the present female rats were in the pubertal stage and their estrous cycles were not controlled, this could have potentially contributed to the higher variability in $\mathrm{CB}_{1}$ and $\mathrm{CB}_{2}$ receptor expression in the female brain.

The higher $\mathrm{CB}_{1}$ mRNA expression levels but lower $\mathrm{CB}_{1}$ protein expression levels in the brain stem of females than males suggest a differential regulation of $\mathrm{CB}_{1}$ mRNA and protein expression between the sexes. While the mechanism is unknown, a potentially greater turnover/degradation rate of $\mathrm{CB}_{1}$ receptor protein in the females could have triggered a need for greater $C_{1}$ mRNA expression. Differential modification of the $C B$ receptor (phosphorylation, glycosylation) induced by sex hormones could cause sex-dependent changes in the affinity and immunogenic activity of $C B$ receptors as detected by the antibodies in this study and others [14]. Furthermore, the greater metabolic rate of cannabinoids reported in the females could cause a parallel increase in $\mathrm{CB}_{1}$ protein turnover and $\mathrm{CB}_{1}$ mRNA expression.

A difference in circulating corticosterone level could also be responsible for the observed sex-dimorphism in $\mathrm{CB}_{1}$ mRNA expression. It is known that females have higher basal corticosteroid levels and greater stress-induced corticosteroid secretion but slower corticosteroid clearance from circulation [8,9]. Chronic exposure to corticosterone, $\mathrm{CB}_{1}$ agonists and cannabinoids has been shown to downregulate $C B_{1}$ receptor density, $C B_{1}$ receptor binding and $C B_{1}$ mRNA expression in brain regions such as cerebellum and hippocampus [15,22,26,37,41].

Although no significant stress effect was found in CB expression in brain stem, this may reflect the technical limitations of present study. Because brain stem tissue homogenates were used in this study, the results are not conclusive regarding changes in $\mathrm{CB}$ receptor expression in specific nuclei of the brain stem. Further immunohistochemistry/in situ hybridization studies are required to determine specific changes in cannabinoid receptor expression in these nuclei after stress and their correlations with behavioral changes in PTSD models. Cannabinoid receptors expressed in the periaqueductal gray, locus coeruleus, raphe nuclei, reticular activating system, solitary tract, vestibular and cochlear nuclei of brain stem are thought to play important roles in the regulation of pain sensation, sleep-awake cycle, acoustic startle response, cardiovascular reactivity that are frequently altered in subjects with PTSD $[1,2,12,30-32,38,48]$.

Since stress enhances norepinephrine (NE) synthesis/turnover in the LC and its subsequent release in the basolateral amygdala via alpha1A adrenergic receptor located in the presynaptic terminals, intense sympathetic activation and local NE release could regulate $\mathrm{CB}$ expression/activity via the release of eCBs. Alternatively, $\mathrm{CB}_{1}$ receptors in the brain stem could potentially interacts with the alpha2-adrenergic autoreceptors to inhibit norepinephrine release from the adrenergic neurons of the locus coeruleus under physiological conditions [42]. Our studies show that the stress differentially suppressed brain adrenergic receptor mRNA expression between male and female rats, with a sex-dimorphism opposing that of brain $\mathrm{CB}$ mRNA expression (manuscript in preparation). Thus, brain $C B$ and adrenergic systems could interact in central regulation of cardiovascular response in stress-induced anxiety disorders [6].

A recent study showed that acute maternal deprivation significantly increased neuronal apoptosis in the cerebellum of male rat pups and that induction was attenuated by inhibiting endogenous cannabinoid (eCBs) degradation [24]. As brain eCBs activity is mainly mediated by $C_{1}$ receptors, that study implicates an important anti-apoptosis role of $\mathrm{CB}_{1}$ receptor in stressed cerebellum. Another brain imaging study showed significant correlations between structural volumes of the cerebellar hemispheres and clin- 
A. Cerebellum

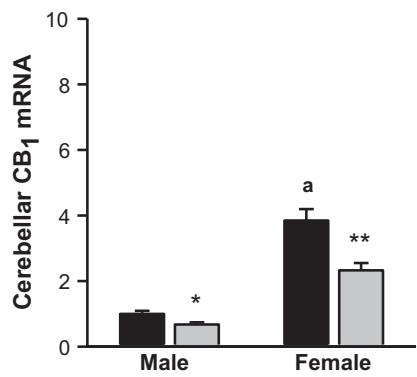

C. Cerebellum

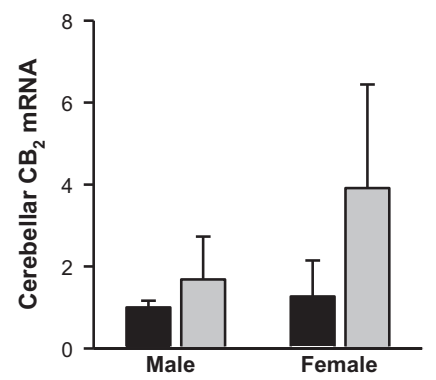

${ }^{*}: \mathrm{P}<0.05$, stress vs control, within sex

**: P<0.01, stress vs control, within sex

$\begin{array}{ll}\text { B. Brain stem } P<0.01 \text {, female control vs male control } & \text { b: } P<0.05 \text {, female control vs male control }\end{array}$

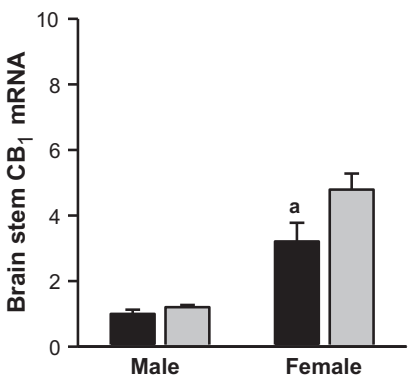

D. Brain stem

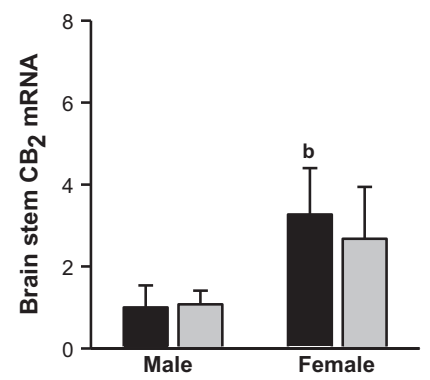

Fig. 1. Effects of gender and stress on $\mathrm{CB}_{1}$ and $\mathrm{CB}_{2}$ mRNA. $(\mathrm{A})$, Cerebellar $\mathrm{CB}_{1}$ mRNA level was significantly higher in the female rats $(n=16)$ than in the males $(n=16$, $p<0.01)$ and in the non-stressed animals $(n=16)$ than in the stressed animals $(n=16, p<0.01)$, respectively. Three days repeated stress down-regulated $\mathrm{CB}_{1} \mathrm{mRNA}$ level in male $(p<0.05)$ and female rats $(p<0.01)$ when compared with same sex controls; $(\mathrm{B})$, Brain stem $\mathrm{CB}_{1}$ mRNA was significantly greater in female rats than in male rats $(p<0.01)$ but no stress effect was found; (C), Cerebellar $\mathrm{CB}_{2}$ mRNA was not affected by sex or stress; (D), Brain stem $\mathrm{CB}_{2}$ mRNA level was significantly higher in female rats than in the males $(p<0.05)$. The mean value of the male control group (mean \pm s.d.) was used as the arbitrary reference $(=1)$. Black column: control rats; gray column, stressed rats, a, $p<0.01$, male control vs. female control; b, $p<0.05$, male control vs. female control; ${ }^{*} p<0.05$; ${ }^{* *} p<0.01$, within-sex 1-way ANOVA.

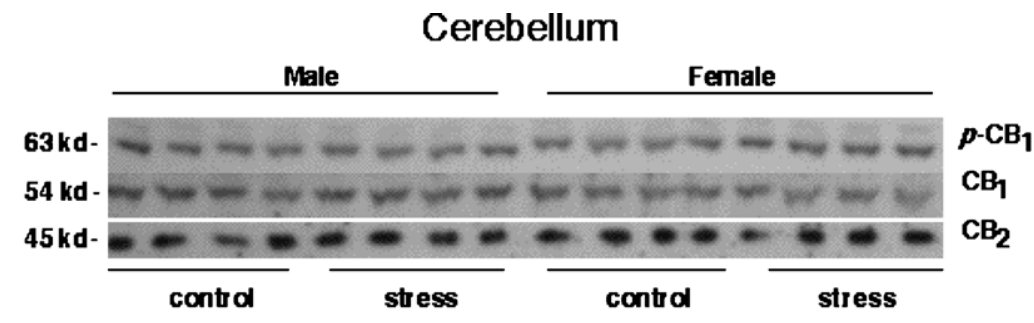

A phosphorylated-CB, protein

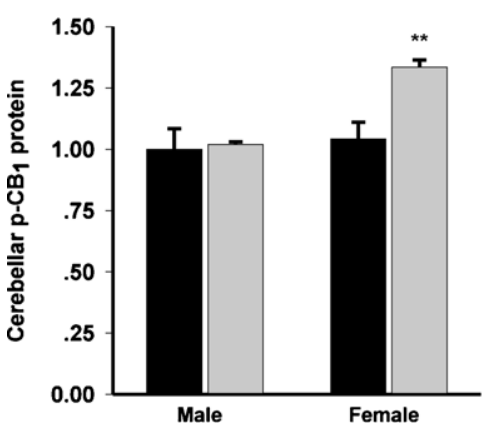

B $\mathrm{CB}_{1}$ protein

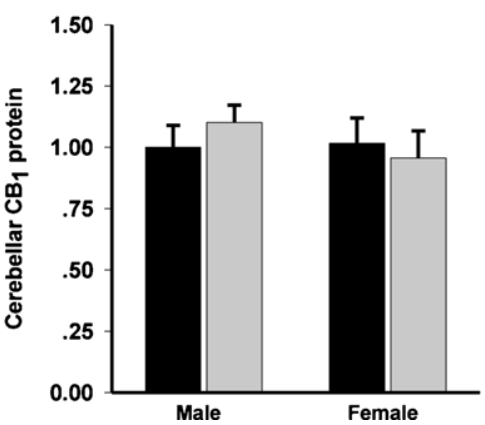

C $\mathrm{CB}_{2}$ protein

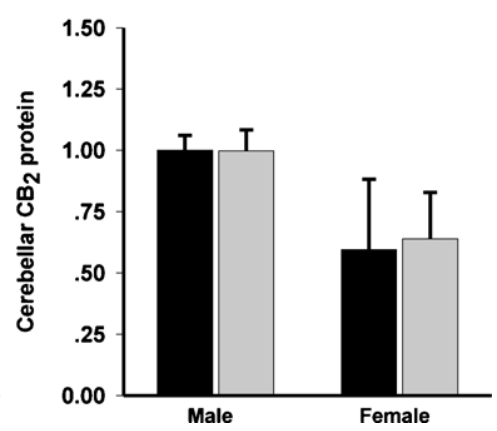

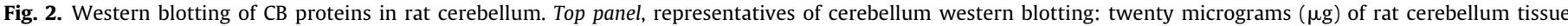

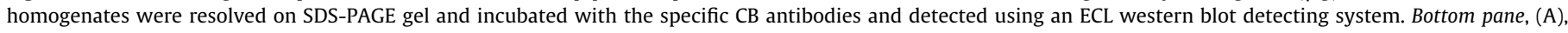

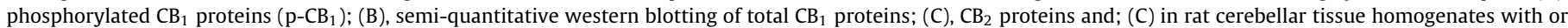

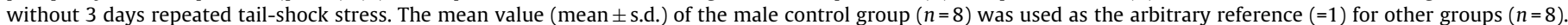

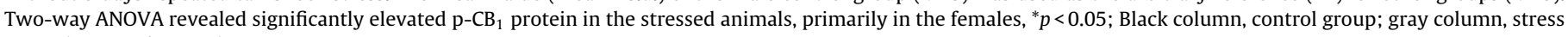
group ( $n=8$ each group). 

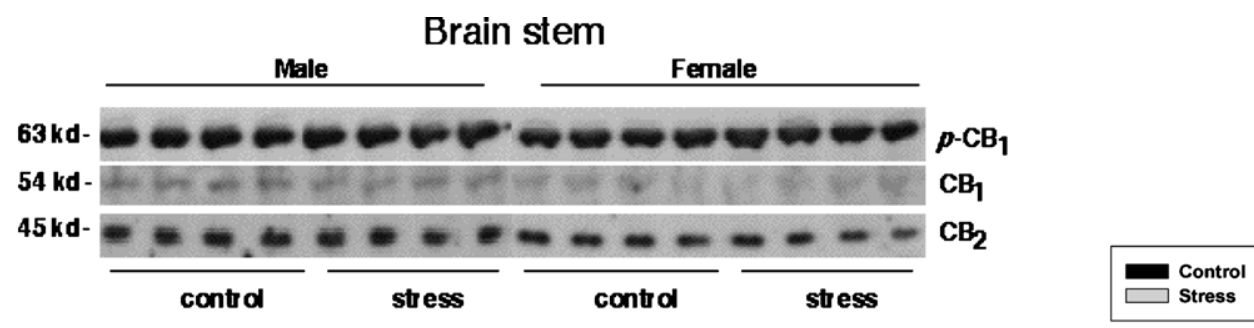

A phosphorylated-CB, protein

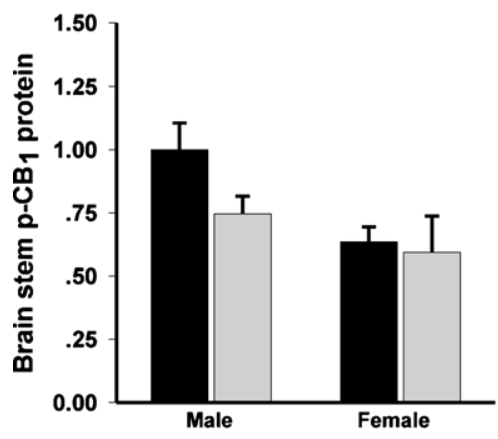

B $\mathrm{CB}_{1}$ protein

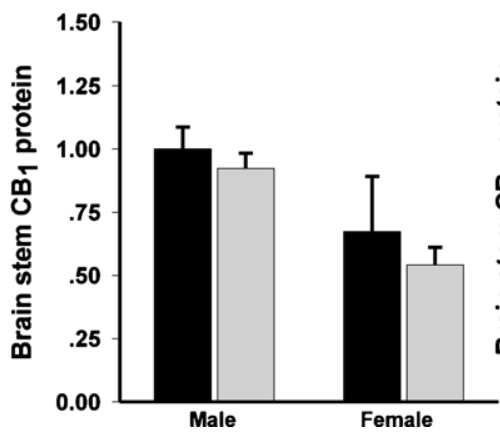

C $\mathrm{CB}_{2}$ protein

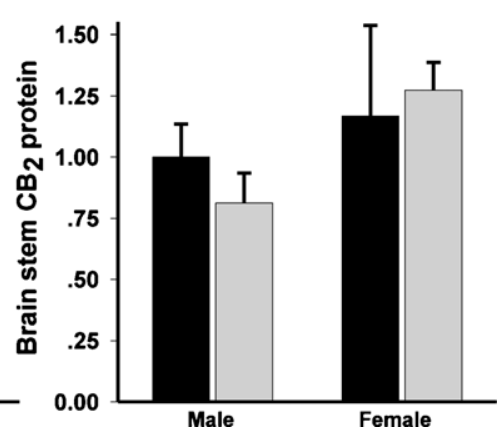

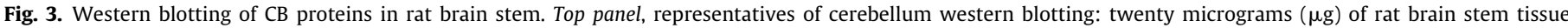

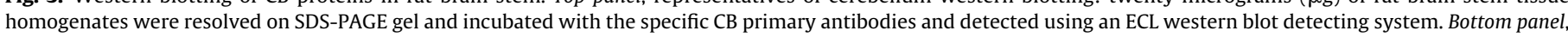

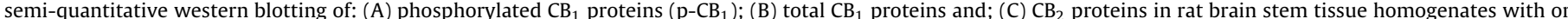

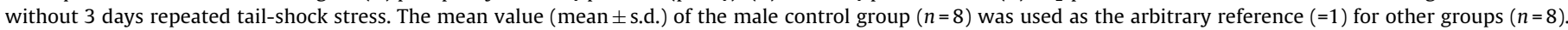
Black column: control group; gray column, stressed group.

ical symptoms in pediatric maltreatment-related PTSD. The PTSD subjects had significantly reduced volume in both the left and the right hemispheres and in total cerebellum volume [11]. These studies implicate a link between stress-induced apoptosis and cerebellum atrophy in PTSD although the exact causative factors and the time course of the atrophy remain to be established. Our study suggests that chronic stress-induced $\mathrm{CB}_{1}$ receptor suppression in early development could be involved in the cerebellar neuronal apoptosis or structural atrophy in PTSD.

It is known that females are more vulnerable than males after exposure to trauma $[4,28]$. The molecular mechanism is unknown. In this study, the stressed female rats showed a greater reduction in $\mathrm{CB}_{1}$ mRNA expression but a greater increase in cerebellum $\mathrm{CB}_{1}$ receptor phosphorylation (at serine 316 ) than the stressed males. Because phosphorylation at serine 316 of $\mathrm{CB}_{1}$ receptor by protein kinase $C$ is a key post-translational regulatory mechanism underlying rapid $C_{1}$ receptor internalization and desensitization by disrupting cannabinoids-mediated activation of inwardly rectifying potassium current and depression of $\mathrm{P} / \mathrm{Q}$-type calcium channels $x$ [18], this phosphorylation of $\mathrm{CB}_{1}$ receptors would represent another novel mechanism of rapid $\mathrm{CB}_{1}$ inhibition in the cerebellum of stressed female rats. Other studies suggest that it is the rate of change rather than absolute level that can bring about swings in mood and anxiety.

It is tempting to speculate that chronic stress-induced $\mathrm{CB}_{1}$ receptor downregulation and inhibition could also be involved in increased marijuana use and cerebellum dysfunction such as altered time sense in PTSD [47]. While further studies are needed to evaluate this notion, impaired time sense has been reported in marijuana users who exhibited cerebellar hypoactivity in response to delta-9-tetrahydrocannabinol [29]. Because marijuana use is common among PTSD subjects and is correlated with the severity of PTSD symptoms [3], the greatly altered $\mathrm{CB}_{1}$ mRNA expression and receptor phosphorylation/desensitization in stressed female cerebellum is consistent with the literature that women are more vulnerable to traumatic stress, become drug dependent more quickly and are more likely to experience craving than men $[4,7,13,17,21,35,43]$.

In summary, we observed significant gender and repeated stress effects and their interaction on $\mathrm{CB}_{1}$ mRNA expression and $\mathrm{CB}_{1}$ receptor phosphorylation in rat cerebellum. The greater $C_{1}$ mRNA expression level in female cerebellum is more vulnerable than that of males after exposure to repeated stress. The rapid $C_{1}$ receptor phosphorylation in cerebellum after stress could also be a biomarker for increased anxiety in females after exposure to repeated traumatic stress. If replicated, these findings could help to design gender-specific pharmacological interventions for stressinduced anxiety disorders.

\section{Conflict of interest}

All authors declare no conflict of interest.

\section{Acknowledgments}

This work was supported by the Center for the Study of Traumatic Stress, Uniformed Services University of the Health Sciences. We would like to thank Drs. Kwang H. Choi and Frances H. Gabbay for comments on the manuscript.

\section{Appendix A. Supplementary data}

Supplementary data associated with this article can be found, in the online version, at doi:10.1016/j.neulet.2011.05.013.

\section{References}

[1] G.J. Asmundson, M.J. Coons, S. Taylor, J. Katz, PTSD and the experience of pain: research and clinical implications of shared vulnerability and mutual maintenance models, Can. J. Psychiatry 47 (2002) 930-937.

[2] G.J. Asmundson, J. Katz, Understanding pain and posttraumatic stress disorder comorbidity: do pathological responses to trauma alter the perception of pain? Pain 138 (2008) 247-249. 
[3] M.O. Bonn-Miller, A.A. Vujanovic, M.T. Feldner, A. Bernstein, M.J. Zvolensky, Posttraumatic stress symptom severity predicts marijuana use coping motives among traumatic event-exposed marijuana users, J. Trauma. Stress 20 (2007) 577-586.

[4] M.A. Bornovalova, P. Ouimette, A.V. Crawford, R. Levy, Testing gender effects on the mechanisms explaining the association between post-traumatic stress symptoms and substance use frequency, Addict. Behav. 34 (2009) 685692.

[5] H.B. Bradshaw, N. Rimmerman, J.F. Krey, J.M. Walker, Sex and hormonal cycle differences in rat brain levels of pain-related cannabimimetic lipid mediators, Am. J. Physiol. Regul. Integr. Comp. Physiol. 291 (2006) R349-R358.

[6] M.F. Braga, V. Aroniadou-Anderjaska, S.T. Manion, C.J. Hough, H. Li, Stress impairs alpha(1A) adrenoceptor-mediated noradrenergic facilitation of GABAergic transmission in the basolateral amygdala, Neuropsychopharmacology 29 (2004) 45-58.

[7] N. Breslau, H.D. Chilcoat, R.C. Kessler, E.L. Peterson, V.C. Lucia, Vulnerability to assaultive violence: further specification of the sex difference in post-traumatic stress disorder, Psychol. Med. 29 (1999) 813-821.

[8] I. Butkevich, V. Mikhailenko, P. Semionov, T. Bagaeva, V. Otellin, A.M. Aloisi, Effects of maternal corticosterone and stress on behavioral and hormonal indices of formalin pain in male and female offspring of different ages, Horm. Behav. 55 (2009) 149-157.

[9] K.A. Caudell, B.B. Gallucci, Neuroendocrine and immunological responses of women to stress, West. J. Nurs. Res. 17 (1995) 672-692.

[10] R.M. Craft, Sex differences in behavioral effects of cannabinoids, Life Sci. 77 (2005) 2471-2478.

[11] M.D. De Bellis, M. Kuchibhatla, Cerebellar volumes in pediatric maltreatmentrelated posttraumatic stress disorder, Biol. Psychiatry 60 (2006) 697-703.

[12] A. Dogrul, L.R. Gardell, S. Ma, M.H. Ossipov, F. Porreca, J. Lai, 'Knock-down' of spinal $\mathrm{CB}_{1}$ receptors produces abnormal pain and elevates spinal dynorphin content in mice, Pain 100 (2002) 203-209.

[13] M. Driessen, S. Schulte, C. Luedecke, I. Schaefer, F. Sutmann, M. Ohlmeier, U. Kemper, G. Koesters, C. Chodzinski, U. Schneider, T. Broese, C. Dette, U. Havemann-Reinicke, Trauma and PTSD in patients with alcohol, drug, or dual dependence: a multi-center study, Alcohol. Clin. Exp. Res. 32 (2008) 481-488.

[14] M. Egertova, M.R. Elphick, Localisation of cannabinoid receptors in the rat brain using antibodies to the intracellular C-terminal tail of CB, J. Comp. Neurol. 422 (2000) 159-171.

[15] F. Fan, Q. Tao, M. Abood, B.R. Martin, Cannabinoid receptor down-regulation without alteration of the inhibitory effect of CP 55,940 on adenylyl cyclase in the cerebellum of CP 55,940-tolerant mice, Brain Res. 706 (1996) 13-20.

[16] L. Fattore, M.S. Spano, S. Altea, F. Angius, P. Fadda, W. Fratta, Cannabinoid selfadministration in rats: sex differences and the influence of ovarian function, Br. J. Pharmacol. 152 (2007) 795-804.

[17] L. Fattore, M.S. Spano, S. Deiana, V. Melis, G. Cossu, P. Fadda, W. Fratta, An endocannabinoid mechanism in relapse to drug seeking: a review of animal studies and clinical perspectives, Brain Res. Rev. 53 (2007) 1-16.

[18] D.E. Garcia, S. Brown, B. Hille, K. Mackie, Protein kinase C disrupts cannabinoid actions by phosphorylation of the $\mathrm{CB}_{1}$ cannabinoid receptor, J. Neurosci. 18 (1998) 2834-2841.

[19] J. Haller, N. Bakos, M. Szirmay, C. Ledent, T.F. Freund, The effects of genetic and pharmacological blockade of the $\mathrm{CB}_{1}$ cannabinoid receptor on anxiety, Eur. J. Neurosci. 16 (2002) 1395-1398.

[20] M. Herkenham, A.B. Lynn, M.D. Little, M.R. Johnson, L.S. Melvin, B.R. de Costa, K.C. Rice, Cannabinoid receptor localization in brain, Proc. Natl. Acad. Sci. U. S. A. 87 (1990) 1932-1936.

[21] C.A. Hernandez-Avila, B.J. Rounsaville, H.R. Kranzler, Opioid-, cannabis- and alcohol-dependent women show more rapid progression to substance abuse treatment, Drug Alcohol Depend. 74 (2004) 265-272.

[22] M.N. Hill, E.J. Carrier, W.S. Ho, L. Shi, S. Patel, B.B. Gorzalka, C.J. Hillard, Prolonged glucocorticoid treatment decreases cannabinoid $\mathrm{CB}_{1}$ receptor density in the hippocampus, Hippocampus 18 (2008) 221-226.

[23] K.C. Koenen, M.J. Lyons, J. Goldberg, J. Simpson, W.M. Williams, R. Toomey, S.A. Eisen, W. True, M.T. Tsuang, Co-twin control study of relationships among combat exposure, combat-related PTSD, and other mental disorders, J. Trauma. Stress 16 (2003) 433-438.

[24] M. Lopez-Gallardo, R. Llorente, A. Llorente-Berzal, E.M. Marco, C. Prada, V. Di Marzo, M.P. Viveros, Neuronal and glial alterations in the cerebellar cortex of maternally deprived rats: gender differences and modulatory effects of two inhibitors of endocannabinoid inactivation, Dev. Neurobiol. 68 (2008) $1429-1440$.

[25] K. Mackie, Distribution of cannabinoid receptors in the central and peripheral nervous system, Handb. Exp. Pharmacol. (2005) 299-325.
[26] R. Malcher-Lopes, A. Franco, J.G. Tasker, Glucocorticoids shift arachidonic acid metabolism toward endocannabinoid synthesis: a non-genomic antiinflammatory switch, Eur. J. Pharmacol. 583 (2008) 322-339.

[27] G. Marsicano, C.T. Wotjak, S.C. Azad, T. Bisogno, G. Rammes, M.G. Cascio, H. Hermann, J. Tang, C. Hofmann, W. Zieglgansberger, V. Di Marzo, B. Lutz, The endogenous cannabinoid system controls extinction of aversive memories, Nature 418 (2002) 530-534.

[28] M. Martin, C. Ledent, M. Parmentier, R. Maldonado, O. Valverde, Involvement of $\mathrm{CB}_{1}$ cannabinoid receptors in emotional behaviour, Psychopharmacology (Berl) 159 (2002) 379-387.

[29] R.J. Mathew, W.H. Wilson, T.G. Turkington, R.E. Coleman, Cerebellar activity and disturbed time sense after THC, Brain Res. 797 (1998) 183-189.

[30] T.A. Mellman, A. Kumar, R. Kulick-Bell, M. Kumar, B. Nolan, Nocturnal/daytime urine noradrenergic measures and sleep in combat-related PTSD, Biol. Psychiatry 38 (1995) 174-179.

[31] C.A. Morgan 3rd, C. Grillon, H. Lubin, S.M. Southwick, Startle reflex abnormalities in women with sexual assault-related posttraumatic stress disorder, Am. J. Psychiatry 154 (1997) 1076-1080.

[32] C.A. Morgan 3rd, C. Grillon, S.M. Southwick, M. Davis, D.S. Charney, Exaggerated acoustic startle reflex in Gulf War veterans with posttraumatic stress disorder, Am. J. Psychiatry 153 (1996) 64-68.

[33] S. Narimatsu, K. Watanabe, I. Yamamoto, H. Yoshimura, Sex difference in the oxidative metabolism of delta 9-tetrahydrocannabinol in the rat, Biochem. Pharmacol. 41 (1991) 1187-1194.

[34] L. Nong, C. Newton, Q. Cheng, H. Friedman, M.D. Roth, T.W. Klein, Altered cannabinoid receptor mRNA expression in peripheral blood mononuclear cells from marijuana smokers, J. Neuroimmunol. 127 (2002) 169-176.

[35] S.E. Nunnink, G. Goldwaser, P.S. Heppner, J.O. Pittman, C.M. Nievergelt, D.G. Baker, Female veterans of the OEF/OIF conflict: concordance of PTSD symptoms and substance misuse, Addict. Behav. 35 (2010) 655-659.

[36] G.T. Okulate, O.B. Jones, Post-traumatic stress disorder, survivor guilt and substance use-a study of hospitalised Nigerian army veterans, S. Afr. Med. J. 96 (2006) 144-146.

[37] A. Oviedo, J. Glowa, M. Herkenham, Chronic cannabinoid administration alters cannabinoid receptor binding in rat brain: a quantitative autoradiographic study, Brain Res. 616 (1993) 293-302.

[38] N. Pole, T.C. Neylan, C. Otte, C. Henn-Hasse, T.J. Metzler, C.R. Marmar, Prospective prediction of posttraumatic stress disorder symptoms using fea potentiated auditory startle responses, Biol. Psychiatry 65 (2009) 235-240.

[39] L.C. Pratchett, M.R. Pelcovitz, R. Yehuda, Trauma and violence: are women the weaker sex? Psychiatr. Clin. N. Am. 33 (2010) 465-474.

[40] F. Rodriguez de Fonseca, M. Cebeira, J.A. Ramos, M. Martin, J.J. Fernandez-Ruiz Cannabinoid receptors in rat brain areas: sexual differences, fluctuations during estrous cycle and changes after gonadectomy and sex steroid replacement, Life Sci. 54 (1994) 159-170.

[41] J. Romero, E. Garcia-Palomero, J.G. Castro, L. Garcia-Gil, J.A. Ramos, J.J Fernandez-Ruiz, Effects of chronic exposure to delta9-tetrahydrocannabinol on cannabinoid receptor binding and mRNA levels in several rat brain regions, Brain Res. Mol. Brain Res. 46 (1997) 100-108.

[42] E. Schlicker, M. Gothert, Interactions between the presynaptic alpha2 autoreceptor and presynaptic inhibitory heteroreceptors on noradrenergic neurones, Brain Res. Bull. 47 (1998) 129-132.

[43] T.P. Sullivan, L.J. Holt, PTSD symptom clusters are differentially related to substance use among community women exposed to intimate partner violence, J. Trauma. Stress 21 (2008) 173-180.

[44] A.H. Tseng, R.M. Craft, $\mathrm{CB}(1)$ receptor mediation of cannabinoid behaviora effects in male and female rats, Psychopharmacology (Berl) 172 (2004) 25-30

[45] A.H. Tseng, R.M. Craft, Sex differences in antinociceptive and motoric effects of cannabinoids, Eur. J. Pharmacol. 430 (2001) 41-47.

[46] L. Uriguen, S. Perez-Rial, C. Ledent, T. Palomo, J. Manzanares, Impaired action of anxiolytic drugs in mice deficient in cannabinoid $\mathrm{CB}_{1}$ receptors, Neuropharmacology 46 (2004) 966-973.

[47] R.J. Ursano, C.S. Fullerton, Posttraumatic stress disorder: cerebellar regulation of psychological, interpersonal, and biological responses to trauma? Psychiatry 62 (1999) 325-328

[48] M.D. Van Sickle, M. Duncan, P.J. Kingsley, A. Mouihate, P. Urbani, K. Mackie, N. Stella, A. Makriyannis, D. Piomelli, J.S. Davison, L.J. Marnett, V. Di Marzo, Q.J. Pittman, K.D. Patel, K.A. Sharkey, Identification and functional characterization of brain stem cannabinoid $C_{2}$ receptors, Science 310 (2005) 329-332.

[49] S. Vetter, A. Rossegger, W. Rossler, J.I. Bisson, J. Endrass, Exposure to the tsunami disaster, PTSD symptoms and increased substance use - an Internet based survey of male and female residents of Switzerland, BMC Public Health 8 (2008) 92. 